\title{
Socio-Economic Impact of Revitalization: The Case of Bandar Seri Begawan, Brunei Darussalam
}

\author{
Fahmi Ibrahim \\ Universiti Teknologi Brunei (UTB) \\ School of Business \\ Email: fahmi.ibrahim@utb.edu.bn \\ Syazana Syazwani Abdul Ghani \\ Universiti Teknologi Brunei (UTB) \\ School of Business
}

Received: April 20, 2018

Accepted: June 8, 2018 Published: June 28, 2018

doi:10.5296/ijrd.v5i2.13024

URL: http://dx.doi.org/10.5296/ijrd.v5i2.13024

\begin{abstract}
Urban revitalization is the process of the city to restore its vibrancy, bringing the city to life, expanding profitable activities, increase in land and economic values and start-up new business ventures. The importance of revitalization can help improve the development to the city in terms of economic, social and cultural. Strategies of revitalization have been implemented through investments, conservation and regeneration that emphasizes to promote tourism, strengthen the capabilities and increase employment opportunities. The aim of this research paper is to revitalize the city of Bandar Seri Begawan into a sustainable environment integrating the interest of residents, businesses and tourists. Subsequently is to investigate the cause and effect of revitalization towards tourism, cultural and social activities. The study focuses on Bandar Seri Begawan, the capital city of Brunei which does not have the usual characteristic of a busy, key economic centre or 'life' of a country which suffers from lack of vitality that it loses out to other cities. Interviews and on-site observations methods were used for this study. The findings demonstrate that revitalization of Bandar Seri Begawan is closely related to the Water Village - Kampong Ayer as it represents the identity of Bandar Seri Begawan. This paper highlights the development of a conceptual framework that can be served as guidelines to revitalize the Bandar Seri Begawan (BSB) into a sustainable city environment integrating all the factors - the diversity of needs of residents, tourists and businesses which also help to understand the cause and effect of revitalization towards
\end{abstract}


tourism, cultural and social activities.

Keywords: socio-economic impact, urban revitalisation, city regeneration, Brunei

\section{Introduction}

Urban revitalizing is the process of reviving or restoring a detrimental city or urban neighbourhood into a lively and vibrant city. Revitalizing actions are required for bringing back the activities and visibility of a city as well as to maintain and improve the development as it can increase the economic, social and cultural development of an area. Revitalization projects affect to some aspects such as improving the quality of life, generating new jobs, transforming and implementing reconstruction of the city in either the value of land or architectural (Holland, 2014). Hence, revitalization is a process aiming at a multi-dimensional reconstruction of downturn areas (Turala, 2005). It does not only involve renovating buildings structure but it should include three other spheres which are social, economic and cultural of a city. In economical aspect, the role of urban revitalizing is to attract new businesses to the area by creating accessibility to the development sites, provide incentives for existing businesses to grow and enhance the marketability. The purpose is to develop the economic growth especially in job creations, economic expansion, encouragement in local entrepreneurship and innovation. In social aspect, urban revitalization helps to create safe, accessible, positive environment and provide better utilities such as pedestrian access, street lighting, sidewalks and other public utilities. The importance of social aspects in urban revitalization is to create sense of place for the public. Finally, in cultural aspect, it preserves the historical integrity of the area.

There are number of evidences why process of revitalization is needed for particular affected cities. For example in Downtown Eastside Vancouver, the conditions of the city deteriorate for the last decades which led to the closure of restaurants and shops, low property cost, drug trade and low investment. The key strategies of revitalization are to increase the demand for the Downtown Eastside's products and services, strengthen the capabilities of local suppliers and increase employment opportunities. One of the actions that are highlighted through the strategies are to take advantage of the key economic drivers such major constructions or projects (Economic Revitalization Plan, 2011). Also Shockoe Bottom in Richmond city has undergone several revitalization since 1980's due to various factors such as flooding, overflow sewer system, storm water management system, residential development, upgrading warehouse district to a commercialized and attractive city. While revitalization seeks to reverse the employment forecast by positioning Richmond to attract bio-sciences, technology, and finance jobs through enhancing Richmond's core strengths, it also emphasizes on the heritage and cultural resources which help promote into tourism, innovation and entrepreneurship, food and dining, and retail and entertainment. This revitalization strategy helps fuse historical and cultural heritages into small and medium enterprises such as using a historical landmark or facilities to establish local shops and markets for the residents.

Urban revitalization has the ability to create models and policies to improve economic activities, local involvements and exploit the maximum potential of the city. Furthermore, revitalization will create more prospects globally and provides economic sustainability. In 
fact, urban revitalization of a city provides economic opportunities in many ways. It helps to generate and provide a sustainable economic, social, cultural and community development. Studies highlight growth opportunities in tourism, arts and culture, education, housing, food processing, apparel and other economic sectors in the Downtown Eastside Vancouver (Vancouver Agreement, 2011). While in Shockoe Bottom, Richmond, the benefits is utilizing vacant land and converts them to a more profitable purpose.

This paper focuses on the socio-economic impact of urban revitalization of Bandar Seri Begawan (BSB) of Brunei Darussalam. Thus, this paper will provide suggestions on transforming the city to an improved modern and vibrant place as well as exploiting the overall potential of the available public spaces in Bandar Seri Begawan. A brief revitalization process in the context of Brunei Darussalam described in the following section.

\section{Literature Review}

\subsection{An Overview of Urban Revitalization in Brunei Darussalam}

Bandar Seri Begawan is the focal city or capital of the Sultanate of Brunei and is also the most densely populated city in the country. Throughout the years, Bandar Seri Begawan had expanded the area to about 100.36 square kilometre of land from 12.87 square kilometres, which accommodated about 140,000 people (as of 2010). However, as a city, it does not have the usual characteristic of a busy, key economic centre or 'life' of a country. It suffers from lack of vitality that it loses out to other centres such as Gadong and Kiulap. The existing infrastructure and connectivity in the centre business district of Bandar Seri Begawan affects the activities being done by the people in the area, as poorly maintained public spaces will gradually lead to the decreasing of the social, economic and environmental value of urban areas. Not only is that, the current facilities and amenities available in Bandar Seri Begawan provided by the government are unfriendly, unsatisfactory and unsafe environment for the public. However, Brunei Darussalam government established several action plans to revitalize Bandar Seri Begawan which is based on National Development Plan 2035. Bandar Seri Begawan needs to be revitalized into the go-to city of the region such as Kuala Lumpur, Manila and Singapore. The approach of urban regeneration in Malaysian cities is to promote a "return to the city", revitalize the city centre, restore activity and implement initiatives to improve the quality of the environment (Azmizam et.al, 2013). While Bandar Seri Begawan can benchmark Kuala Lumpur as a model to understand how successful their urban revitalization Brunei is unique country where philosophy of Melayu Islam Beraja (MIB) needs to be applied into the revitalization process.

\subsection{Overview of Revitalization Concept}

Various terms were referred to these revitalization processes that commonly used interchangeably. Spandou et. al (2010) has identified the terms such as regeneration, renewal, redevelopment,rehabilitation, restoration, conservation, reconstruction, refurbishment and renaissance. In the early 1970's, urban revitalization was first referred to public efforts to revitalize the aging and decaying inner cities. Between 1950s and 1970s, urban revitalization, the process associated with wholesale clearance of run-down city sections and replacing them 
with new buildings was applied to revitalized deprived urban areas and improve living and social conditions in cities such North America and Western Europe (Temelova, 2009). Urban revitalization is one of the important strategies to improve and redevelop potential areas of commerce and urban growth. It is also known as urban regeneration. It is a strategic activity, engaged in short-term measures for immediate difficulties and long term approaches to avoid future problems. It is an interventionist approach, best achieved through partnership working, intending to benefit a range of organisations, agencies and communities. It is related to specific needs and potentials in an individual region, city, town, or neighbourhood and linked to other appropriate policy areas and programmes (Roberts and Sykes, 2000).

The evolution of urban revitalization is closely related to the purpose of why it was implemented in the first place. Urban culture-led regeneration strategies originally were used to deal with multilevel urban socioeconomic problems, such as declining urban centres and economic restructuring such in the post-industrial cities within North America and Western Europe. With overall globalisation trends, the governance mode of urban managerialism has gradually been replaced by that of urban entrepreneurialism (Harvey, 1989). Since 1980s, there has been a sharp upturn in urban tourism (Galdini, 2007). However, aggressive upgrades of urbanization can lead to a serious downfall in several areas. After the second half of 20th century, either due to the end of World War II and new job opportunities, or being a popular touristic destination, some cities rapidly grew leading to decentralization and abandonment of historic city cores (Ertan and Egercioglu, 2015). It has mostly affected the current or previous establishment of the urban area. Gaining modern infrastructure also can severely affect historical and cultural areas. This is clearly worsened when the initial revitalization is very successful and gaining more profit. Therefore urban management need to be analysed properly with effective decision-making. Several inter-related factors have played a part in this process: the need to revitalize into and rehabilitate the historic centres of cities, wider-ranging and more diversified cultural pursuits, consumers' interest in the heritage and urban development and their search for things to do and for spending opportunities (Galdini, 2007). For instance, old buildings represent memory of the place which provides emotional values to the area (Fielden, 2003).

As shown in Figure 1, Goodey et al. (2013) has created a theoretical framework for heritage-led urban regeneration which involves the need of the investment towards heritage. The investment towards conservation-regeneration includes property, land, capital, human resources and heritage resource. 


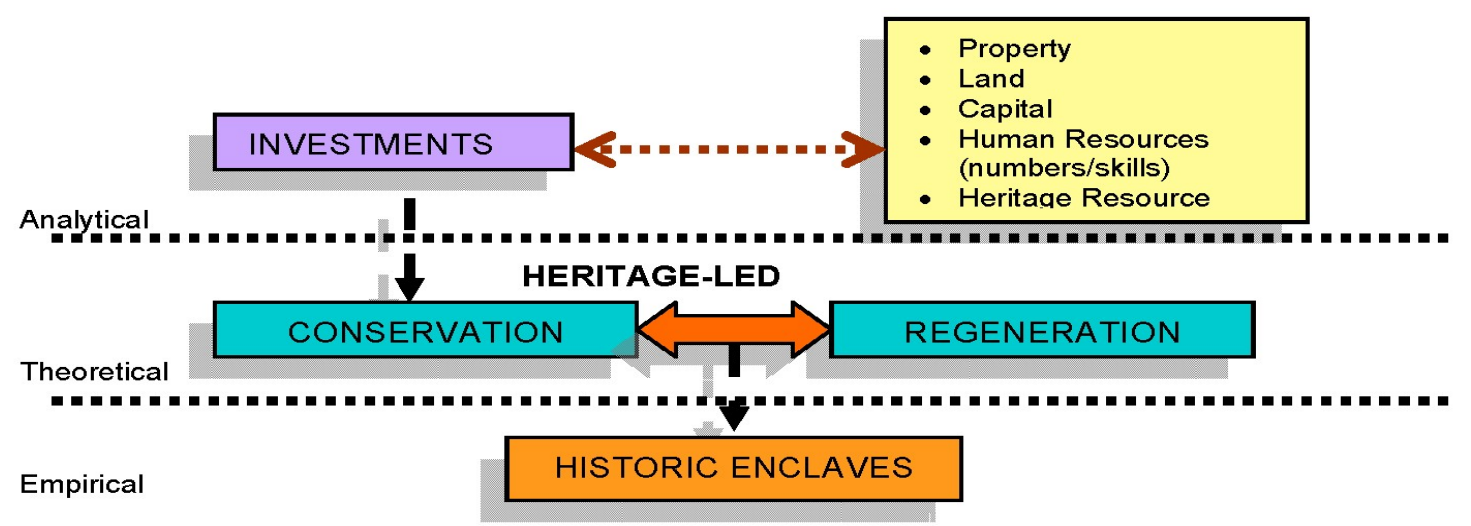

Figure 1. Theoretical Framework for Heritage-Led Urban Regeneration

Source: Adapted from (Said, Syed Zainal, Thomas and Goodey, 2013, p.268).

According to Spandou et.al (2010), urban revitalization or redevelopment has emerged as a response to the urban decline problem. Basically, urban regeneration aims to address issues that are associated with change in the economy and employment, economic competitiveness, social exclusion, community issues, vacant and deteriorated sites in cities, new land and property requirements, environmental quality and sustainable development (Turok, 2004, Keles, 2003, Roberts, 2000). As a result, a variety of terms has been used interchangeably refer to this redevelopment process. These include regeneration, renewal, redevelopment, rehabilitation, conservation, restoration, revitalization, reconstruction, refurbishment and renaissance. However, Vileniske (2014) stated the use of the term "revitalization" adapted from the research by Polanska (2008) on the urban decline and revitalization in the post-Communist Poland using the example of Gdansk. Most urban regeneration projects target tackling crime issues as well either by physical design improvement or capacity building programmes for local unemployed people (Goksin \& Muderrisoglu, 2005). However, Temelova et. al (2010) use the example of Prague describe the revitalization of the historic neighbourhoods more as negative process with undesirable effects of massive touristification and commercialization.

Radoslav et al. (2011) describe the revitalization has a three level process from the case of of the city center of Timisoara in Romania: 1) re-functionalizing of structures 2) recreating public spaces and 3) reorienting events. Likewise urban revitalization can be categorised into three classifications; 'people', 'businesses' and 'place' (Turok's, 2005). In terms of people, revitalization aims to enhance skills, capacities and aspirations to enable them to participate in and benefit from opportunities. Whereas in business aspects, revitalization aims to improve economic competitiveness in terms of business performance, to create more local jobs and prosperity. Finally, to attract both people and business, revitalization aims to improve the general appeal of a place. Miles (2005) points out that the successful factors of culture-led urban regeneration lie in whether cultural projects can engage with people's sense of 
belonging in a place. The place image is significant to the role of cultural-product industries (Scott, 1997). The images of cultural cities are delivered into the global or regional marketplace through selling local cultural products to global tourists (Lash and Urry, 1994). The classifications above is line with Scott (1997) has indicated that place, culture and economy are closely interwoven together. Hence, this shows that urban regeneration is related with economic, social and cultural in order to have a sustainable, vibrant, lively and business oriented city.

\subsection{Significance of Socio-Economy and Culture in Urban Revitalization}

The cultural and social contributions through cultural festivals are crucial elements in revitalising an urban area (Quinn, 2005). Miles and Paddison (2005) further suggest that the local government should not underestimate the degree to which culture-led regeneration projects depend on how well they engage with local communities and cultures, as compared with short-term economic promotion in such culture-led regeneration projects. A successful urban revitalization such heritage site preservation is part of an economic and social development plan which considers the urban site users' ideas as an important input (Ertan, Egercioglu, 2015). In fact, urban revitalization can promote a better quality of life which can uphold the economic and social renewal.

In globalisation, it is important for cities to attract and bring in the creative economies. The outcomes of urban revitalization can help improve the capacity and infrastructure of cities to meet the standards creative economies demand (Goksin \& Muderrisoglu, 2005). Since tourism is also part of creative economies, it is an important part of the city's economy and contributes to the standard of living of the community (Galdini, 2007). According to Howkins (2001), creative economy is "the transactions of creative products that have an economic good or service that results from creativity and has economic value". Department of Culture, Media and Sport (DCMS) of the UK define the creative economy as industries which have started from a pool of individual's creativity, skill and talent and which have a potential for economic growth and job opportunities through the generation and exploitation of intellectual property (DCMS, 2015). Capacity building programmes also enable under qualified people gain qualifications for the new service sectors including creative sectors (Goksin \& Muderrisoglu, 2005). By supporting educational facilities, regeneration projects can help develop the skilled workforce creative sector need (Goksin \& Muderrisoglu, 2005). In sum, the development of the creative economy is in relation with the 'investments' element-human resources number/skills that is required for urban revitalization as argued by Goodey et. al (2013) shown in Figure 1 in previous section.

Urban revitalization can also be interpreted as creating a new economy. The new economy has changed the factors of attraction in cities. Cities have to find new way to attract residents, workers and businesses. It needs a new kind of workforce who should be well-educated, skilled and flexible. Cities should improve their educational facilities and demands a high quality of life. Cities should control crime and blight and enhance cultural amenities. The new economy is global and it necessitates strong links with national and international economies. As this new economy needs a new infrastructure, cities should provide necessary 
digital infrastructure and upgrade existing ones. It is a regional economy. Cities have to find ways to overcome the division in the suburban areas of the metropolitan regions (Goksin \& Muderrisoglu, 2005).

\subsection{Impacts of Urban Revitalization}

Urban Revitalization is implemented for the main reason to obtain positive results. For example preservation of historical buildings combined with developing modern infrastructure can benefit the city or area in terms of tourism, job creations and business opportunities. Economic impact from tourists' arrival will contribute in preserving and restoring historic buildings and monuments (Galdini, 2007). With constant monitoring and adjustments, a city will be able to grow and sustain. It does not happen overnight, for instance, over the past 22 years, in Main Street, USA revitalization efforts have created 227,000 jobs and 56,000 businesses and have saved 89,000 historic buildings all across the country (Retail Wire, 2002). On the other hand, Melaka in Malaysia is still continuing its development and with the benefits gained, the future seems promising for the historic city centre (Ertan \& Egercioglu, 2015). Melaka has become one of the necessary places to visit in Asian nation with almost 25 million tourists arrived in 2012 (Ertan \& Egercioglu, 2015).

The fusion of modern and historical areas can be beneficial in urban revitalization. Old buildings do not always need to serve it previous functions. They can be incorporated with new functional ways which are accepted by the local community as well as tourists. For example the new patterns in Copenhagen's city space in 1968. The first outdoor cafes opened and started attract the people into the streets for political and cultural happenings. In a few decades, the city changed from devoted working city and basic necessities into a city of leisure and enjoyment which became the sole focus of city space in Copenhagen. Over the past 40 years, more people use the central city and spend more time there and improve their public spaces as enliven and enrich urban life (Gehl et al., 2006). This has improved tourism sectors to a high degree. As tourism grows, additional opportunities are created for investment, development, and infrastructure spending (Galdini, 2007). Tourism can lead to further improvements in public transportation and utilities; such improvements in turns benefit tourists and residents (Galdini, 2007). However, higher demand for products, services, housing and property may increase prices that in turn will increase the cost of living (Galdini, 2007).

Another important positive impact is environmental. Areas that own abundant natural environment and great scenic beauty can attract tourists and new residents who seek emotional and spiritual connections with nature (Galdini, 2007). Therefore, natural environments are preserved, protected, and kept from further ecological decline (Galdini, 2007). This will also cater the market of nature lovers to experience nature. Environmental also helps in improving the economic aspects of urban revitalization such as land use and clean environment. It helps create a more attractive, healthy community and in time will grow bigger and bigger provided enough facilities and infrastructure to support the public. For example, in Soweto, South Africa more land has been allocated for housings, schools, parks and industrial as well as commercial expansion to make Soweto cleaner, attractive and more 
efficient for communities to live (Morontse, 2010). In sum, a healthy city is a symbol of community pride and history. It boosts the economic health and quality of life where it creates jobs, incubates small businesses, reduces sprawl, protects property values and increase the community's options for goods and services.

While urban revitalization has positive impacts, there evidences demonstrate on the negative impacts on urban revitalization. In terms of environmental impacts, urban renewal generally refers to improvements to the quality of the built environment. This includes restoration of old buildings, physical improvements to urban layout, removal of dilapidated buildings and construction or enhancement of infrastructure (Holmes et.al, 2015). Despite urban revitalization creates major transformation from old town to become modern cities that will attract more people to open businesses and boost the economy, this can pose disagreements in demolishing heritage buildings which will disrupt the process of revitalization. However, by achieving a certain understanding and consideration, urban revitalization can be done in improving urban condition as well as preserving historical areas. Melaka, Malaysia is a good example of historical tourism that could be managed. Even though there are challenges during the preservation process, Melaka is a successful project that lives dynamically in today and present the historical face of its diverse background at the same time (Ertan \& Egercioglu, 2015).

Correspondingly to historical buildings, cultural heritages also play an important role when considering to urban revitalization. The public, who have built up cultural norms and heritage within the area, may fell reluctant to see modern changes to their community. Urban heritage is what defines the identity of a city but once it starts to get destroyed; the identity of the urban area starts to diminish as well (Ertan \& Egercioglu, 2015). For example Hong Kong built a new heritage for foreigners but not keeping the traditional (Cheung, 1999). A lot of heritages have been removed which made Hong Kong lost its uniqueness. It has been emphasized that Hong Kong should protect its own cultural identity by promoting its historical and cultural heritages as tourist attractions rather than just building those glamorous shopping malls (Henderson, 2001). By all means urban revitalization in Hong Kong is more focused on the physical environment than concern on the economic and social environment. For example, some elder residents were asked to move to a new district for the sake of urban redevelopment. The elders have to adapt to a new, unfamiliar environment and perhaps lose their social connections with friends and neighbours, which would lead to social problems (Edmond, 2012). Further many local businesses and traditional economics activities were destroyed due to the redevelopment that would lead to unemployment and the loss of local community (Edmond, 2012).

It is argued that economic rhetoric of culture-led urban regeneration driven by competitive forces perhaps short sighted and may have unavoidably caused some problems and drawbacks (Zukin, 1995; Harvey, 2001; Bassett et al., 2005). The uneven effects of economic regeneration, for example, have resulted in a lack of place, identity-building and local cultural meaning. Although culture-led projects have the potential to contribute to local economic development, less attention has been given to how to integrate the existing cultural resources of local communities into such urban regeneration (Myerscough, 1988). 


\section{Research Methodology}

Qualitative methodology approach is adopted for this study to allow identifying the current issues related to future changes and development to Bandar Seri Begawan. Given that the research on the study of urban revitalization does not impact directly towards economics but also have an impact on social and environment, qualitative approach is most appropriate to uncover relevant themes and indicators of the study. This approach is utilised on similar study by Douglas and Ennis (2011), investigating on cultural investment that affect to economic impacts i.e. direct and indirect investment, visitor and residents spending and business location etc. and also has an impact towards social i.e. confidence and change in perception of area and person (Douglas and Ennis, 2011). To evaluate the research study, qualitative method plays an important role in order to have subjective data and information towards the study. Qualitative approach can provide a more detail perspective such as determining the long-term effect, internal issues and hidden obstacles because $t$ is argued that quantitative approach is neglected the perspective of the people, opinions and social issues that are crucial in urban revitalization in the long run (Douglas \& Ennis, 2011).

In this research study, an open-ended interview was conducted. According to Creswell (2003), interview is one of the four basic types of data collection in qualitative study which involves unstructured and generally open-ended questions that are few in number and intended to elicit views and opinions from the participants. The interviews which were conducted in this research were informal interviews with the local and foreign respondents. There were 31 local respondents which only focused on Tutong, Belait and Temburong districts only. The reason for these selections because to get different perspective from "local tourists". And 20 foreign respondents were also interviewed for this research. The interviews were taken place during the 'Bandarku Ceria' every Sunday. In addition, a formal interview was conducted with the government officer at Town and Country Planning department, Ministry of Home Affairs that engaged in Bandar Seri Begawan planning. The interviews are crucially important in helping design the data gathering for the research study. All in all this study has high degree of data validity as several experts opinion were generated through interviews who involved in Brunei Master Plan 2035, tourism sector, public works department and the development sector. This claim is supported by Esther and Edwin (2014) study in Hong Kong, in order to have concrete-valid data towards a study in revitalizing historic buildings in urban renewal, a qualified expert should have at least fifteen years of experience in the field of urban design, planning, architecture and heritage conservation.

\section{Findings and Discussions}

There were number of themes uncovered through the research as follows;

\subsection{Positive Identity of Bandar Sri Begawan}

When mentioned about the identity of Bandar Seri Begawan (BSB), it refers to people's understanding and views of the capital city. Majority of the respondents described Bandar Seri Begawan as a Melayu Islam Beraja (MIB) city concept. This means that the buildings, 
and the people within the city center are conducting in a manner than are within the Malay culture, Islamic guidance and the monarch expectations. From this analysis, it can be said that MIB philosophy has been instilled in the heart of the local community.

"BSB identity is Islamic country because Brunei uphold the MIB concept" (Respondent 6)

"MIB city because the only city in the world which adopts this philosophy and shows true culture and value of Islamic nation" (Respondent 10)

"Identity of BSB has MIB feeling due to Brunei is practicing Islamic monarchy" (Respondent 9)

The second top response towards the identity of Bandar Seri Begawan is the Sultan Omar Ali Saifuddien (SOAS) Mosque. It is consider the symbol of the city as well as the country itself. It is one of the most beautiful mosques in Asia Pacific region. It symbolized the Islamic culture of Brunei and a go-to place for tourists.

"SOAS Mosque is the most attractive building in Brunei" (Respondent 16)

"SOAS Mosque is the most unique mosque in South East Asia" (Respondent 3)

Brunei has been able to maintain its cultural heritage which Bruneians are proud of. This also counts as an identity and it help create a uniqueness that only Brunei have.

"A city with cultural values because most of the buildings in BSB represents the identity of Malay Brunei” (Respondent 8)

"The old buildings such the oldest 'tamu' should be preserved" (Respondent 1)

Without doubt the location of BSB along the Brunei river Water Village - Kg Ayer is the main landmark of BSB. Kampong Ayer is also one of the highest responses in describing BSB. It is filled with rich historical and cultural heritage of Brunei. It is a residential area that accommodates approximately 30,000 people along Brunei River and the community is very close where long line of generations has live there. It is also recognized by Asian countries as a unique landmark of Brunei and being called as the Venice of the East. The main mode of transportation there is using water taxi and at certain areas by car.

"It is the heart of the country where lies the past history of the city as well present and the future" (Respondent 5)

"Identity of BSB a capital which foundation built side by side with Water village" (Respondent 7)

Another response towards identifying Bandar Seri Begawan is the peacefulness of the city which is very obvious whether in term of national security, low crime rate, low disaster or serene environment.

"Peaceful, clean and tidy city and not too busy" (Respondent 2)

"Lively and peaceful during the weekends particularly with activities of Bandarku Ceria" (Respondent 15) 
"Peaceful but only few entertainments in the capital" (Respondent 3)

"Small but clean and organized city" (Respondent 5)

"Peaceful and a beautiful city" (Respondent 13)

"It's generally very peaceful and you feel safe and I think that's very important thing" (Respondent 17)

\subsection{Cultural Heritage as a Product of Bandar Seri Begawan}

$90 \%$ of the local respondents agreed that cultural can attract tourist as well as boost the economy in the future. Further, the rest of the respondents are inclined to agree as well however depends on the target market, how it is managed and implemented. These shows that cultural heritage plays an important role in economic growth of tourism. For Brunei, it has the potential to be a GDP contributor other than oil and gas industry. It promotes tourism as well as enriching the local culture and the uniqueness that Brunei can offer. The key factors in improving cultural heritage are through preservation and selling the heritage.

"Brunei has strong cultural heritage such Water Village-Kampung Ayer" (Respondent 11)

"The identity of BSB is the culture and arts" (Respondent 23)

"Brunei has a rich culture" (Respondent 10)

Responses above confirmed that majority respondents (90\%) agreed that BSB is appropriate to be cultural heritage capital than a business centre. For a country that is rich in culture, it would be a waste to not exploit the resources available. The tourism based on cultural heritage is significantly low is not because it is unfavourable market, but because many people still do not know the varieties of culture that Bandar Seri Begawan has to offer. In a socio-economic perspective, promoting cultural heritage can provide long lasting impressions among the local community, wonderful experience for tourists and a reason for families to be together and enrich culture within the city center.

Bandar Seri Begawan is a city that has experience different era of governance and different generations of residents of Kampong Ayer. This shows how much historical value and cultural building that still stands throughout the years. Some are being maintained and some need further improvements. This reality has been observed by the local community and wishes that those buildings be part of their heritage and be fully utilized for the convenience of our local consumers as well as tourists. They wish to portray what their heritage has to offer whether to establish cultural activities within the facilities or simply present a visual image for everyone to see.

\subsection{Tourism as an Opportunity for Revitalization}

Tourism is one of most significant social and economic forces in the world today. Thousands of visitors who come do not only bring money but they also transform the city for better or worse. Brunei needs a sustainable tourism to develop assets of tourism industry; intact nature, rich and diverse culture, the satisfaction of visitors and the positive attitude of the resident 
population.

"Brunei has pristine rainforest with exotic wildlife. Borneo jungle is one of the oldest in the world that is main attraction for jungle trekking" (Respondent 10)

"Brunei has a lot of interesting culture like religion, food and habit. So many people want to visit Brunei once they know the country. BSB is good working place because if we get tired on work, we can relax easily with beautiful views, slow and peaceful atmosphere of the city" (Respondent 36)

"Water Village just like Venice of the East!" (Respondent 38)

"Tourism can help the economy of Brunei because there is cultural heritage can use as tourist spots. In Korea, palaces they make it as tourist spot, and they got business blooming by selling souvenirs from that palace and can bring memories with them" (Respondent 19)

Nevertheless, tourism is the industry that need to be developed in terms 'tourism product' and the infrastructure that support the industry.

"There could be more attractions than the current ones. Some of the places such Tasek Lama needs to be properly maintained and playground not repaired" (Respondent 16)

"Jerudong Park is fine actually, but it totally needs to be revamped. We need more place to promote our culture and heritage where some areas in bad state with abandoned buildings" (Respondent 22)

"More events and festivals about Brunei's culture and art which is attraction to tourists when they are coming and visit Brunei” (Respondent 23)

"Tourist spots should more to be developed such as theme park and shopping spot" (Respondent 25)

"Organise fun, music concert big events that will highlight the name of country and attract more tourist to come and spend their money here" (Respondent 26)

"I think there are various sites around the city could be developed more that could be become better tourist sites. I live down on Kota Batu near maritime museum and others interesting places and I don't think anyone really knows about it" (Respondent 50)

"Bandar $\mathrm{Ku}$ Ceria event is one good initiative made so far. In my opinion a similar concept can be developed at night time where people can feel more relax and enjoy the cool air. When Pokemon Go was popular, night businesses were booming in certain places" (Respondent 10)

This demonstrates domestic tourism need to be improved as approximately only $26 \%$ of the local respondents have preferred to enjoy the tourism offered in Brunei itself compared to overseas. While they enjoyed the current attraction spots and sightseeing choices that are offered domestically they still believe that there are still room for improvements that will further pull them even more into local Brunei's tourism. In contrast a total of $68 \%$ of the local respondents have chosen to go abroad for their vacation rather than in Brunei. Most of the reasons provided are push factors that Brunei needs to improve and create better attractions 
and tourist spots as well as varieties of efficient public transportation system. Current tourist spots needs proper maintenance and preservation to ensure sustainability.

Conversely, there are compelling evidence of foreign tourists who are visiting Bandar Seri Begawan. The first thing that came into their mind is that Bandar Seri Begawan is a small city with fewer places to visit. They can walk around the entire city center within a day. They also noticed that the road systems are organized and motorists are well disciplined. They also love the scenery, cleanliness and the peaceful environment of Bandar Seri Begawan. Mostly, they are surprised that there are only few people everywhere and some describe it as being desolate. 'BandarKu Ceria' is the best experience they have during their stay. They can see how friendly and joyful Bruneians are and many other activities can be done during the event. Other than that, they love the tourist attraction available within the city center such as the Royal Regalia and Omar Ali Saifuddien Mosque, although it would be nice if there are more places they can experience. Most of the respondents mentioned that their country have similar kinds of attractions such as shopping centers, museums, and amusement parks, in fact, even more than Bandar Seri Begawan. For this reason, we can analyse the strengths of Bandar Seri Begawan and how Brunei can utilized these attraction spots to its full capacity.

\subsection{Improvement Current Infrastructure and Practices}

From the perspectives of the local community, it is crucial to understand what kinds of improvements that they need which can be looked into. The purpose of revitalization of Bandar Seri Begawan is to ensure the city is lively and can improve economy, social and cultural. Therefore the needs of local as well as tourists need to be taken into account.

Most of the respondents have brought up the issue of public transportation. Currently, the public transportation system is not satisfactory among our local community. They still prefer to drive their own car. Issues of public transportation mentioned are unreliable and slow waiting time, difficult to get a taxi, and expensive taxi fare. Public transportation is limited and it is hard for them to move around other than walking. By improving the public transportation, it will help reduce traffic congestion, reduce carbon footprint, better time management for commuters, a healthier lifestyle, and provide easier access to different key areas for tourists.

"Improve the public system of transportation for tourists as they can easily access public transportation all over Brunei" (Respondent 9)

"The Eco - Corridor along Kedayan river, Sungai Kebun Bridge and Temburong bridge in master plan is excellent infrastructure" (Respondent 13)

"Water Village (Kampung Ayer) and Tamu Kiangeh need to be upgraded" (Respondent 11)

"Development of network of community services for public and more innovative businesses run by local entrepreneurs" (Respondent 12)

Water Village - Kampong Ayer is an icon for Brunei and one of the main tourist attractions. It is necessary to ensure Kampong Ayer is well maintained to preserve its historical value as well as fully utilized its potential to promote tourism, safety of the residents and generate 
business opportunities. A limited selection of shopping complex is another issue that need to be addressed. Consumers are looking for varieties of clothing, food, electronic devices, entertainment and local souvenirs in a single or multiple, indoor area. It can help boost economy through foreign direct investment as well as local entrepreneurs. It also generates job opportunities for local and possibly attracts more foreign expertise into Brunei's markets. Rather than planning to shop abroad, local consumers can just get what they need within the country.

Throughout the city, security and convenience of non-motor vehicles users is also important. It provides a safe and relaxing environment for pedestrian and cyclists to move about in the city. In a country that is mostly sunny and humid, shadings plays an important part of the infrastructure. Therefore, the development of these facilities needs to be improved. Currently, Bandar Seri Begawan is still the main focus for national events and festivals throughout the year such events are the National Day. His Majesty's Birthday, Bandarku Ceria, Islamic event and other related celebrations. If all of these events with addition to new, attractive and inspiring ones, these can attract more people to come to Bandar Seri Begawan to enjoy themselves and experience the cultures. Other findings refer to the general improvements in the products and services, infrastructure and overall environment.

\section{Conclusions and Recommendations}

Urban revitalization is the process to ensure the city restores its vibrancy, bringing the city to life, expanding profitable activities, increase in land and economic values and start-up new business ventures. It is one of the important strategies to improve and redeveloped potential areas of commerce and urban growth. Revitalizing actions are required for bringing back the activities and visibility of a city as well as to maintain and improve the development as it can increase the economic, social and cultural development of an area. Bandar Seri Begawan is the capital of the Sultanate of Brunei and is also the most densely populated city in the country. In 1970's, it was once a centre of major business activities. However, throughout the years, the city was deteriorating which resulted in decaying and abandoned buildings and declining in businesses. It does not have the usual characteristic of a busy, key economic centre or 'life' of a country. It suffers from lack of vitality that it loses out to other centre.

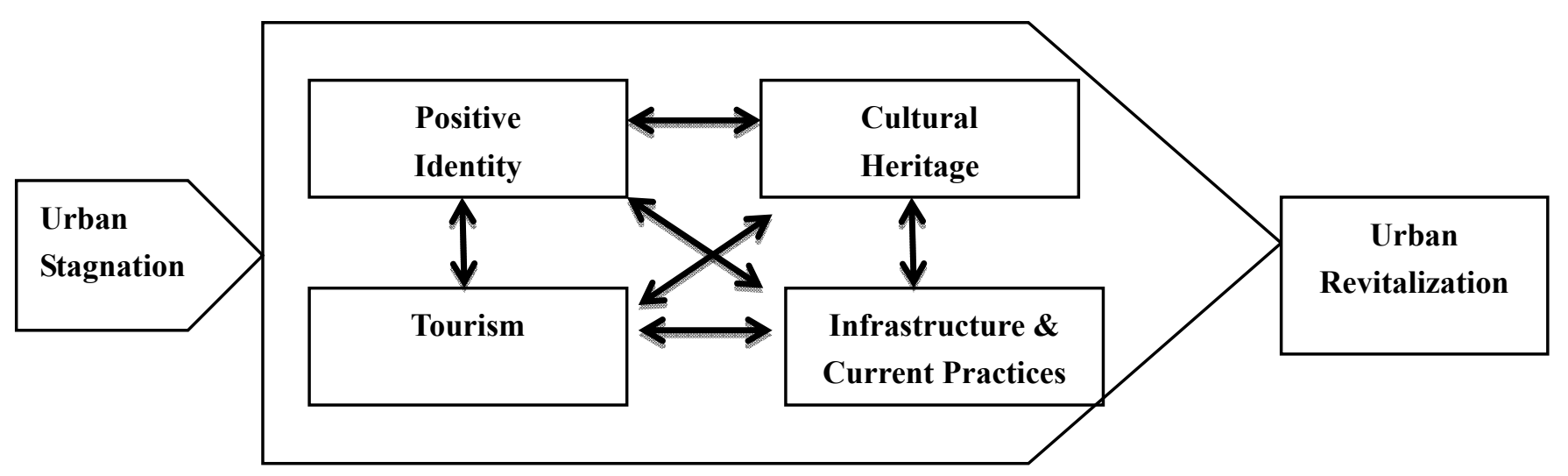

Figure 2. Urban stagnation-revitalization conceptual framework 


\section{Ml Macrothink}

International Journal of Regional Development ISSN 2373-9851 2018, Vol. 5, No. 2

Based on the findings enabled this research is to propose a conceptual framework (see Figure 2) that can be served as guidelines to revitalize the Bandar Seri Begawan (BSB) into a sustainable city environment integrating all the factors - the diversity of needs of residents, tourists and businesses which also help to understand the cause and effect of revitalization towards tourism, cultural and social activities. The framework above demonstrates all those inter-related aspects must be taken into account for effective revitalization process. Urban revitalization takes complex characteristics; in Brunei case it involves creating positive identity of city/country, restoration and preservation of cultural heritage, enriching tourism industry and improving infrastructure and current practices. It is evident that Bandar Seri Begawan has great potential in being one of the top cities in Asia particularly with respect to eco-tourism. This research will help develop a deeper understanding about the strength and weakness of Bandar Seri Begawan and how to improve its potential with the help of the guidelines of the propose framework.

\section{References}

Azmizam Abdul Rashid, Dahlia Rosly \& Shamsaini Shamsuddin (2013). Revitalizing Urban Development in Malaysia through the Implementation of Urban Regeneration Programme. Proceedings of Urban Affairs Association 43 ${ }^{\text {rd }}$ Annual Conference. Building the $21^{\text {st }}$ Century City: Inclusion, Innovation and Globalization. April 3-6. San Francisco California. Urban Affairs Association. Universiti of Milwaukee.

Bassett, K. (1993). Urban Cultural Strategies and Urban Regeneration: A Case Study and Critique. Environment and Planning, 1773-1788.

Bassett, K., Griffiths, R. and Smith, I. (2002). Testing governance: partnerships, planning and conflict in waterfront regeneration. Urban Studies, 1755-1777.

Bianchini, F. (1993b). Remaking European Cities: The Role of Cultural Policies. Manchester: Manchester University Press.

Bianchini, F., \& Parkinson, M. (1993). Cultural Policy and Urban Regeneration: The West European Experience. Manchester: Manchester University Press.

Brunei Darussalam Long-Term Development Plan: Wawasan Brunei 2035, Outline of Strategies and Policies for Development (OSPD) 2007-2017, National Development Plan (RKN) 2007-2012 (2007). Brunei Darussalam: The Government Printing Department, Prime Minister's Office.

Campbell, D. (2013). East Bay Bicycle Coalition: Oakland, Hayward Ready to Become 'Green' Cities. Retrieved from https://www.ebbc.org

Cheung, S. C. H. (1999). The Meanings of a Heritage Trail in Hong Kong. Annals of Tourism Research, 570-588.

Christopher, L. (2012). How to revitalize Blighted Areas without Increasing Taxes. Retrieved from

http://plannersweb.com/2012/11/how-to-revitalize-blightedareas-without-increasing-taxes/ 
Colantonio, A., \& Dixon, T. (2011). Urban Regeneration \& Social Sustainability: Best Practice from European Cities. Retrieved from http://samples.sainsburysebooks.co.uk/9781444329452_sample_416350.pdf

Creswell, J. W. (2003). Research Design: Qualitative, Quantitative, and Mixed Methods Approach. Thousand Oaks: SAGE Publications.

Department for Culture Media \& Sport (DCMS). (2015). Official Statistics: Creative Industries Economic Estimates January 2015 -Key Findings.

Douglass, G., \& Ennis, N. (2011). Working Paper 48. Culture and Regeneration - What Evidence is there of a Link and How can it be Measured? London: Greater London Authority

Economic Revitalization Plan. (2011). Vancouver Agreement. Retrieved from http://www.vancouveragreement.ca/wp-content/uploads/041100_dtesworkplan.pdf

Edmond, C. M. H. (2012). Renewing the Urban Regeneration Approach in Hong Kong. Retrieved from http://ssweb.cityu.edu.hk/download/RS/EJournal/journal6.pdf

Ertan, T., \& Egercioglu, Y. (2015). The Impact of UNESCO World Heritage List on Historic Urban City Centers and Its Place in Urban Regeneration: The Case of Melaka, Malaysia and Tire, Turkey. Procedia - Social and Behavioral Sciences, 591-602.

Fielden, B. M. (2003). Conservation of Historic Buildings (3rd ed). Oxford: Elsevier.

Francaviglia, R. V. (1996). Main Street Revisited. Iowa City: University of Iowa Press.

Galdini, R. (2007). Tourism and the City: Opportunity For Regeneration. International Multidisciplinary Journal of Tourism, 2, 95-111.

Gehl, J., Gemzoe, L., Kirknaes, S., \& Sondergaard, B. (2006). New City Life. Retrieved from http://www.pps.org/reference/howtorevitalizeacity/

Goksin and Muderrisoglu. (2005). Urban Regeneration: A Comprehensive Strategy for Creating Spaces for Innovative Economies. Proceedings at $41^{\text {st }}$ Isocarp Congress, Istanbul. Retrieved from http://www.isocarp.net/data/case_studies/619.pdf

Griffiths, R. (1995). Cultural Strategies and New Modes of Urban Intervention. Cities, 12(4), 253-265.

Hanaoke, K. (2007). Gentrification and Degentrification: A Case Study of Mount Pleasant and the Woodland Cluster. (The American University). ProQuest Dissertations and Theses. Retrieved from http://search.proquest.com/docview/304893634?accountid=14585.

Harvey, D. (1989). From Managerialism to Entrepreneurialism: The Transformation in Urban Governance in Late Capitalism. Sweden: Geografiska Annaler, 3-17.

Harvey, D. (2001). Spaces of Capital: Towards a Critical Geography. New York: Routledge.

Hawkins, J. (2001). The Creative Economy: How People Make Money from Ideas. United Kingdon: Allen Lane. 
Henderson, J. (2001). Heritage, Identity and Tourism in Hong Kong. International Journal of Heritage Studies, 219-235.

Holland, S. (2014). Weaving policy, people \& place together, revitalizing broad way east what does revitalizing mean? Retrieved from http://www.mpnh.org

Holmes, K., Hughes, M., Mair, J., \& Carlsen, J. (2015). Events and Sustainability. United Kingdom: Routledge.

Kazis, N. (2010). StreetsBlog: Coming Soon: Ped-Friendly "Urban Umbrellas" for NYC Sidewalks.

Retrieved

from

http://www.streetsblog.org/2010/01/21/comingsoon-ped-friendly-urban-umbrellas-for-nyc-sid ewalks/

Keles, R. (2003). Urban Regeneration in Istanbul. Paper presented to Priority Action Programme, Regional Activity Center.

Lash, S., \& Urry, J. (1994). Economics of Signs and Space. London: Routledge.

Turala, M. (2005). Revitalisation of Cities - Preconditions, Requirements and Instruments. A Case Study of Lodz. $\quad$ Retrieved from https://www.researchgate.net/profile/Maciej_Turala/publication/242129177_Revitalisation_o f_cities_preconditions_requirements_and_instruments_A_case_study_of_Lodz/links $/ 0 \mathrm{a} 85 \mathrm{e}$-5 3b50ace18db1000000.pdf

Maimunah, R., Dasimah, O., Rozyah, M. Y., \& Zalina, S. (2015). Revitalization of Urban Public Spaces: An Overview. https://doi.org/10.1016/j.sbspro.2015.08.187

Markusen, A. (2006). Urban development and the politics of a creative class: Evidence from a study of artists. Environment and Planning A: Economy and Space, 38, 1921-1940. Retrieved from http://journals.sagepub.com/doi/pdf/10.1068/a38179

Miles, S. (2005). 'Our Tyne': Iconic Regeneration and the Revitalisation of Identity in Newcastle-Gateshead. Urban Studies, 913-926.

Miles, S., \& Paddinson, R. (2005). The Rise and Rise of Cultural-led Urban Regeneration. Urban Studies, 833-839.

Morontse, S. P. (2010). The Impact of Urban Renewal Projects for Enhanced Sustainable Livelihoods in Soweto. Retrieved from http://dspace.nwu.ac.za/bitstream/handle/10394/12820/Morontse,\%20SP.pdf

Myerscough, J. (1988). The Economic Importance of the Arts in Britain. London: Policy Studies Institute.

Ng. (2005). Quality of life perceptions and directions for urban regeneration in Hong Kong. Social Indicator Research. Retrieved from http://link.springer.com/chapter/10.1007\%2F1-4020-3602-7_15\#page-1

O’Connor, J. (1998). Popular Culture, Cultural Intermediaries and Urban Regeneration. 
London: John Wiley and Sons.

Office of the Deputy Prime Minister. (2003). Sustainable Communities: Building for the Future. London. Retrieved from http://webarchive.nationalarchives.gov.uk/20120919132719/www.communities.gov.uk/docu ments/communities/pdf/146289.pdf

Ozdil, T. R. (2006). Assessing the Economic Revitalization Impact of Urban Design Improvements: The Texas Main Street Program. Retrieved from http://oaktrust.library.tamu.edu/bitstream/handle/1969.1/5885/etd-tamu-2006A-URSC-Ozdil. pdf

Pew Partnership. (2003). Solution for America. United States, University of Richmond.

Polaska, D. (2008). Decline and Revitalization in post-communist urban context: A Case of the Polish City - Gdansk. https://doi.org/10.1016/j.postcomstud.2008.06.002

Policy Research Group. (2013). The Creative Economy: Key Concepts and Literature Review Highlights.

Retrieved from https://cch.novascotia.ca/sites/default/files/inline/documents/creativeeconomy-synthesis_201 305.pdf

Presidential Urban Renewal Programme. (2001). Business plan for Urban Renewal Programme: Khayelitsha and Mitchelsplain. Cape Town South Africa.

Radoslav, R., Branea, A. M., Gaman, M. S., \& Morar, T. (2011), Revitalization Strategy of Urban Spaces through a Holistic Vision - Case Study Timisoara, Romania.

Quinn, B. (2005). Arts Festivals and The City. Urban Studies, 927-943

Roberts, P., \& Skyes, H. (2000). Current Challenges and Future Prospects. Urban Regeneration: A Handbook. London: Sage Publications, 295-314

Retail, W. (2002). Survey Shows Strong Downtown Economies. Retrieved from http://www.retailwire.com/discussion/survey-shows-strong-downtowneconomies/

Said, S. Y., Syed Zainal, S. S., \& Thomas, M. G., \& Goodey, B. (2013). Sustaining Old Historic Cities through Heritage-Led Regeneration. In Zubir, S. S., and Brebia C. A. (Eds.), Sustainability City (Vol. 179). Wit Press.

Scott, A. J. (1997), The Cultural Economy of Cities. International Journal of Urban and Regional Research, 323-329.

Shockoe Economic Revitalization Strategy. (2011). Retrieved from http://www.richmondgov.com/EconomicCommunityDevelopment/documents/ShockoeFinalD raftStrategy11_1.pdf

Sibel, P., \& Neslihan, D. (2010). Urban Regeneration and Local Expectations: The Case of the Central Garage District, Bursa-Turkey. World Applied Science Journal, 8(8). Retrieved from http://www.idosi.org/wasj/wasj8(8)10/18.pdf 
Spadou, M., Garcia, C., Martinez, L., \& Macario, R. (2010).Urban Revitalization, Land Use and Transport: Participatory Scenario Building Process in Portugal. Retrieved from http://www.academia.edu/1405703/URBAN_REVITALIZATION_LAND_USE_AND_TRA NSPORT_PARTICIPATORY_SCENARIO_BUILDING_P ROCESS_IN_PORTUGAL

Storm, E. (2002).Converting Pork into Porcelain: Cultural Institutions and Downtown Development. Urban Affairs Review, 3-21.

Tamelova, J. (2009). Urban Revitalization in Central and Inner Parts of (Post Socialist) Cities: Conditions and Consequences. Retrieved from https://web.natur.cuni.cz/ksgrrsek/novyurrlab/user/documents/jajinek/Jana/Regeneration2009. pdf

Temelová, J., Dvoráková, N., \& Slezáková, A. (2010). Senior Residential Satisfaction in Prominent Quarter of Prague. Social Studies, 7(3), 95-113.

Turok, I. (2005). Urban Regeneration: What can be done and what should be avoided? Proceedings in Istanbul 2004 International Urban Regeneration Symposium. Workshop of Kucukcekmee District: Kucukcemee Municipality Publication.

Vileniske, I. G., \& Urbonas, V. (2014). Urban Regeneration in the Context of Post Soviet Transformation: Lithuanian Experience. Retrieved from http://fulltext.study/preview/pdf/1038014.pdf

Whitt, J. A. (1987). Mozart in the Metropolis: The Arts Coalition and the Urban Growth Machine. Urban Affairs Quarterl, 28-35.

Wynne, D. (1992). The Cultural Industry: The Arts in Urban Regeneration. London: Avebury.

Yung, E., \& Chan, E. (2013). Formulating Social Indicators of Revitalizing Historic Buildings in Urban Renewal: Towards a Research Agenda. Department of Building and Real Estate the Hong Kong Polytechnic University. Retrieved from https://www.irbnet.de/daten/iconda/CIB_DC26614.pdf

Zukin, S. (1995). The Cultures of Cities. London: Blackwell.

\section{Copyright Disclaimer}

Copyright for this article is retained by the author(s), with first publication rights granted to the journal.

This is an open-access article distributed under the terms and conditions of the Creative Commons Attribution license (http://creativecommons.org/licenses/by/3.0/). 